\title{
A Brief Look from the Neurosurgical Perspective into the Philosophy of Science
}

\author{
Tayfun HAKAN \\ Fatih Sultan Mehmet Teaching and Research Hospital, Neurosurgery Clinic, Istanbul, Turkey \\ Corresponding author: Tayfun HAKAN tayfunhakan@yahoo.com
}

\section{ABSTRACT}

Philosophy meaning "love of wisdom" is a research product of people who think, produce ideas, and transfer these ideas to each other. The philosophy of science questions the concept of "scientific knowledge" and analyzes the procedures and observations for a logical explanation of facts from a scientific perspective that is important for natural sciences in general and neurosurgery in particular. Observation, experimentation/measuring, and scientific explanations are examples of the methods of the philosophy of science.

Besides the theories, facts, and logical/strong evidences, there are numerous concepts of the philosophy of science in neurosurgery that are difficult to understand in practice. For example, do "numbness," "pain," and "visual analog score" mean the same to the patient and the doctor? Can mechanical low back pain and instability be a real subject of the philosophy of science in the same phenomenon; how can a concept of movement-"instability" explain the cause of a concept of sensation-"pain"? Can concepts from entirely different categories like "dynamic stabilization" occur in the same scientific explanation?

There are also some problematic terms that remain unsolved such as "observable" and "unobservable," which gradually increase with technological advances in neuroscience.

In conclusion, these types of subjects not only affect the basis of our "scientific knowledge" but also the relationships with our patients and colleagues; it is essential to "understand" and be "understandable." We should bring "scientific perspectives" to these issues by using critical, analytical, and integrative features of philosophy.

KEYWORDS: Knowledge, Neurosurgery, Philosophy, Philosophy of science, Science

ABBREVIATIONS: CSF: Cerebrospinal fluid, ICP: Intracranial pressure, LBP: Low back pain, VAS: Visual analogue scale

\section{INTRODUCTION}

"Science without philosophy, facts without perspective and valuation, cannot save us from havoc and despair. Science gives us knowledge, but only philosophy can give us wisdom."

Will Durant

$\mathrm{P}$ hilosophy as passed on to English directly from Latin and French means "love of wisdom." (26). It originates from Greek (philo = loving + sophia = knowledge, wisdom). Philosophy can also be defined as "love of knowledge" when it considered as an academic discipline for the study of the fundamental nature of knowledge, reality, and existence (27). Philosophy is merely the rational, abstract, and methodical consideration of reality as a whole or of fundamental dimensions of human existence and experience (25). Philosophy is the activity of understanding and making sense of the world or existence by "going beyond" or "looking from above" perceptual experiences. Philosophy tries to understand fundamental truths like knowledge, reason, and mind; while it also questions the "established values." It is a dynamic phenomenon; a research product of people who think, produce ideas, and transfer these ideas to each other.

Tayfun HAKAN : (1D) :0000-0003-1444-7076 
One of the tasks of philosophy is to aid the development of the part of the world that is open to change.

Philosophy of science is a discipline of philosophy that researches the observational and/or experimental sciences (9). The subject, purpose, and method of this discipline are the science itself, to investigate what science is, and analytics and using the data of the history of science, respectively. In other words, the philosophy of science questions the concept of "scientific knowledge" (1). Ordinary people mostly respect scientists and the scientific information they provide in daily life, but they do not criticize the science; it is the task of the philosophy.However, we must realize that there is no sharp distinction between science and philosophy of science.

Aristotle is often regarded as the first philosopher of science; he created the philosophy of science by analyzing certain problems that emerged in connection with explanations (15). He developed the terminology of science such as faculty, mean, (maxim), category, energy, and principle that are used frequently in scientific speeches (5).

The developing technology and differentiation of neurosurgery threatens to lose both its holistic perception and a systematic approach to the patient (14). Neurosurgical practice, in terms of its general patterns is characterized by being logical and trying to understand the case; to gather an anamnesis, to examine, to perform the laboratory and radiological examinations of the patient, and to reach a conclusion after evaluating them as a whole, is actually a philosophical approach itself (Figure 1). Each of the "diagnosis-operation-result" concepts that we use in daily practice belong to a philosophical category called "preaction-action-result."
This report is about a small introduction to the philosophy of science with some examples from the neurosciences. The philosophy of science is also concerned with logical positivism - a school of philosophy, and/or basic issues like verifiability, the place of metaphysics in scientific function, falsifiability, scientific development, normal science, and scientific revolution. Each of these subjects deserves detailed and comprehensive separate studies by experts.

The goal of this manuscript is to embark on a small journey to the realm of philosophy and to evoke curiosity in readers about the philosophy of science.

\section{DISCUSSION}

As neurosurgeons, we not only examine or operate on the patient but also obtain new information about the different mechanisms of the brain and spinal cord caused by disease. The crux behind the formulation of new concepts and theories is to understand and accurately use this information, while also providing appropriate scientific explanations to them, which constitutes the philosophy of science that we develop unawares.

There are so many issues to be discussed in the philosophy of science that you can find yourself drowning in depths of information. This article was not written to make indisputable claims and judgments about the philosophy of science but to highlight some subjects with brief mentions and to encourage readers to think. As Durant said, science needs philosophythe analysis of scientific methods and the coordination of scientific purposes and results; without this, any science becomes superficial (6).

Philosophy of Science in Neurosurgery

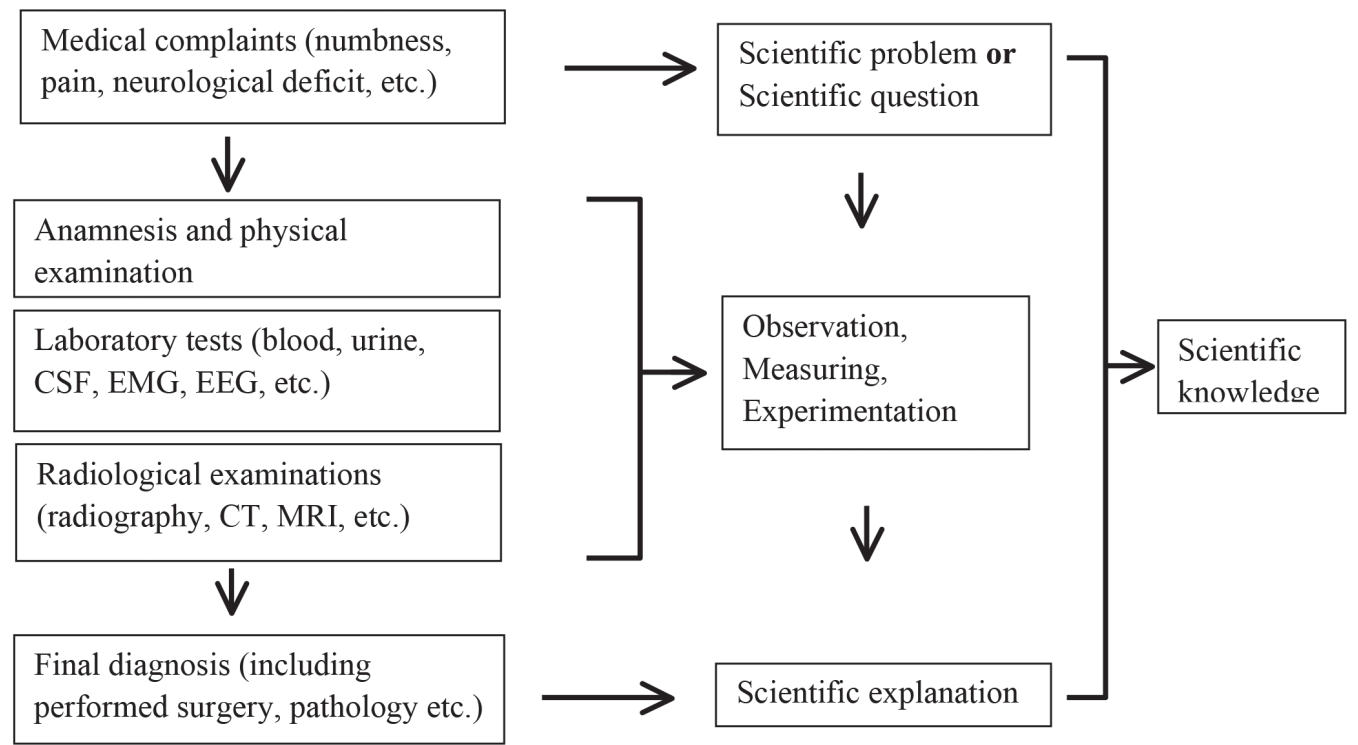

Figure 1: Reflection of some concepts of philosophy of science to the neurosurgery practice. 


\section{Science and Scientific Problem}

According to numerous philosophers of science, every problem or concept has ontological, epistemological, and methodological features (9). The philosophers of science investigate the subject, purpose, and methods of science to understand what science is. The concepts are questioned to establish a relationship between the subject and ontology, purpose and epistemology, and process and methodology. In philosophy, in a nutshell, ontology is the study of what there is (21), and epistemology is the philosophical study of the nature, origin, and limits of human knowledge, and sometimes it is referred to as the theory of knowledge (7).

One of the basic problems of science is the ontological problem of the subject matter and scope of science. Scientific realist philosophers generally argue that scientific theories are capable of being true, and entities postulated by science are existent, whereas anti-realists maintain that only observable things do exist. This is one of the many endless philosophical discussions.

We talk about a scientific problem when there is something that we do not understand or there is an observation that has a contradiction with valid or unchanged theories. Recalling the saying "the only thing that does not change is change itself," we can state this as a proviso against the term "unchanged" and move ahead. For example: As it is well known, neck stiffness is a common clinical sign we face in emergency units. This is a simple example of a scientific problem; neck stiffness is a scientific observation based on the neurological examination of a patient; is it a case of meningitis or subarachnoid hemorrhage? Here, we perform experiments to help us understand the etiology of meningeal irritation, the "scientific problem."

\section{Philosophical Approach to the Observation Concept as a Scientific Method}

The definition of concepts is significant in philosophy, considering that the lack of given definitions is one of the characteristics of Socratic search. According to Socrates, although people frequently use numerous important concepts, they continue their lives without completely understanding what they mean. Through his famous philosophical dialogues, Socrates enabled the people who were ignorant about the discussed concepts to comprehend the in-depth meaning of these concepts using the questioning method.

Like experiment and measuring, observation is a method employed by physical sciences that can provide access to knowledge in philosophy and is accepted as one of the scientific methods. Science uses commonly observable facts, events, processes, and relations to explain many theories (2). Here, science is faced with the question of what is observable or unobservable. According to Klemke et al., scientists often speak of ordinary things called as observables, but they also often talk about unobservables. If that is the case, ordinary things such as bone, muscle, vessel, blood, nerve are "observable" for neuroscientists; however, things like pain, numbness, tingling, confusion, and weakness are "unobservable" (12).
At this point, the philosophy of science begins to seek answers to some questions; are these unobservable concepts an entity? If so, what are the correspondences of these concepts in the everyday practice of the neuroscientist? What does the word "numbness" mean in terms of our daily concrete world? What does the word "pain" mean, and how can it be changed depending on the same neurological conditions even in the same patient? Do we, neuroscientists have clear, understandable, and indubitable answers to these questions?

The Visual Analogue Scale (VAS) is a widely used observational scale for measuring the intensity of pain in adult patients since the 1920s (19). It is used in almost all medical disciplines and naturally in neurosurgery for evaluating the pain of the patients in many areas like for subarachnoid hemorrhages, nervous system tumors, spinal surgeries, entrapment neuropathies, decompression for cranial rhizopathies, etc. Are we sure that the word "visual" is the same for all practitioners? Does pain have the same explanation or meaning for both patients and health workers? In practice, we know that many concepts such as "pain" are subjective and do not always imply the samesense of "pain" for the same condition, even in the same patient, especially as the degree of the pain may be different depending on the severity of the condition or the person's pain withstanding threshold. It appears that we should endeavor to solve the issue of "the same concepts referring to different meanings" in the name of "certainty of scientific knowledge."

Such kind of practical problems that emerging from interactive differences are now being overcome with the help of appropriate anamnesis, examination and imaging methods.

Barseghyan et al., say that "observable" refers to typically any process, structure, or entity that can be perceived with the naked eye, while "unobservable" refers to any process, structure, or entity that cannot be observed with the naked eye (2). The "with the naked eye" concept is used for things that can be perceived without any technological help. According to this, such things as Schwann cell, astrocyte, axon, internal elastic lamina, smooth muscle cell, which can only be seen only with the help of a microscope, are all unobservable. Actually, we could find out this rule based on our studies with tumors; with the increase in molecular studies, we have to change our image-based diagnostic systems regularly. What a nice irony: What we observed with a microscope was not actually what they looked like; they were really unobservable!

Nowadays, the philosophers of science are asking more specific questions; do our scientific theories appropriately describe both observables and unobservables (2)? What do the neuroscientists think about it?

The World Health Organization classification of tumors of the central nervous system includes 59 types/subtypes of tumors originating from only neuroglial cells (diffuse astrocytic and oligodendroglial tumors 20, other astrocytic tumors 5, ependymal tumors 8 , other gliomas 3 , neuronal and mixed neuronal-glial tumors 12, and tumors of the cranial and paraspinal nerves 11) (16). Research on molecular genetics engendered great changes to the histologic classification of brain tumors, helped the diagnosis, and provided the 
prognostic and predictive value of brain tumors. However, we still use nearly the same treatment modalities according to the tumors with different genetic profiles. Do we see all the glial tumors to be same based on nature, structure, growth pattern, behavior, and response to the same surgery, chemotherapy, and radiotherapy, etc.? Or do we feel helpless as the practitioners of science? Do we have correct theories describing these diseases and accurate plans to cure them?

From the perspective of both philosophy and neuroscience, there is no doubt that scientists will get correct answers as long as they ask the "right" questions as a result of Socratic search, especially based on Philosophers' method of seeking truth and knowledge through asking questions.

\section{Scientific Explanation}

The scientific explanation is another subject of the philosophy of science that requires the conditions to be correct, and it is used for the explanation of phenomena through scientific methods. Science needs the help of identification for a scientific explanation. A phenomenon is an object, fact, or occurrence that is perceived or observed (24). For example: Brain tumorrelated epileptic seizure is a phenomenon, an observable event that can be documented easily. Electrophysiological monitoring and radiological investigation of the brain with electroencephalography and magnetic resonance imaging, respectively, reveal the tumor in detail and provide "scientific explanations" of the epileptic seizure.

\section{Nature of the Philosophy of Science or Functions of the Philosophy of Science}

The philosophy of science is basically a philosophical interpretation of scientific function. In 1971, John Losee, wrote in detail about the scope of the philosophy of science (15). He expressed four perspectives on the philosophy of science to establish a basis for the historical survey.

1) The formulation of world views consistent with important scientific theories. The philosophy of science tries to develop and find out the effects of this significant scientific progress. For example: Recent molecular research on glioblastoma led to the identification of novel immunotherapeutics for treatment (11). Assumed treatment methods, such as tumor vaccine, may require a different philosophical perspective on deadly diseases such as glioblastoma. When malignant diseases become easily curable with vaccines, the questioning and reidentification of what malign means will be inevitable based on the philosophy of science.

2) A display of scientists' assumptions. The scientists' approach to the universal laws of physics may be statistical, mechanistic, and theological (target-specific). The philosophy of science tries to help scientists to be aware of their own assumptions concerning their scientific works. Indeed, scientific knowledge relies on a few basic assumptions that are worth acknowledging such as (3):

a. There are natural causes for things that happen in the world around us. For example: the Monro-Kellie doctrine is a basic principle of neurophysiology and neuropathology that is fundamental to an understanding of the increased intracranial pressure (ICP) syndrome (17). It states that the volume of the cranium is constant and equal to the total volumes of the brain, cerebrospinal fluid (CSF), and intracerebral blood. Any increase in the volume of one of the intracranial constituents must be compensated by a corresponding decrease in the volume of another. What does the word "volume" mean, what is the "decrease" or "increase" in volume? What is "constant," and what kind of equality can there be between the volumes of three variable structures and the cranium?

b. Evidence from the natural world can be used to learn about those causes. Science assumes that we can learn about gravity, can perform experiments with falling objects, and we can observe how gravity works (3). For example: In neuroscience, the laws of gravity are widely used to create a spinal cord injury or a diffuse brain injury in some neurotrauma models $(8,18)$. On the other hand, gravity is used to protect the neural structures during some neurosurgical operations. The semi-sitting position is preferred by neurosurgeons because gravity helps to drainage blood and irrigation out of the surgical field (28). It facilitates cerebral venous decompression, CSF drainage, and decreasing ICP, which helps cerebellar retraction and allows for better surgical exposure of the depth of the cerebrum. The philosophy of science should analyze the procedures and provide logical explanations of emerging benefits.

c. There is consistency in the causes that operate in the natural world. The same natural events cause the same outcomes independent of when and where things happen. For example: Total separation of the common peroneal nerve due to laceration causes foot drop in all humans without exception.

As you can see, science has so many topics that neuroscientists could specify their purpose of research according to the basic assumptions listed above. The philosopher of science can approach scientific studies to find out these type of assumptions in them.

3) It is a discipline that analyzes and clarifies the concepts and theories of the sciences. Scientists usually do not question the meanings of the concepts they often use in their research. The task of the philosophy of science is to clarify these concepts and explain exactly what they mean (1). For example: Today, "dynamic stabilization" has become a very popular and ambitious concept in spine surgery. In the daily practice of spine surgeons, to use both "dynamic" and "stabilization" concepts together as an adjectival clause in a sentence is very natural and ordinary; however, the explanation of what the terms "dynamic," stabilization," and "dynamic stabilization" mean, and the meaning of being both dynamic and stable at the same time is the task of the philosophy of science. Besides the philosophical questioning, the clinical problems that emerged led to scientific questioning, which resulted in scientists searching for new solutions, and the hybrid systems appeared (10).

4) A second-order criteriology. Here, criteriology is the study of the validity of reasoning and the criteria necessary to achieve knowledge (4). A second-order criteriology is a concept that includes the efforts to find out the methods and 
structures of the science, and what the science means to us. In philosophy, "a second-order" criteriology is a research topic accepting itself as a research topic, and the questions are "a second-order" questions (1). The difference between a scientific function and a non-scientific function, the conditions of a successful scientific explanation, and what exactly does scientific progress mean are some examples of second-order questions.

It is obvious that there is a difference between practicing science and thinking about how science ought to be practiced; the analysis of the scientific method-a secondorder discipline, is a good guide for understanding this issue (Table I) (15).

\section{The Analysis of a Scientific Method as a Second-Order Discipline}

The analysis of procedures and logical explanation of facts is only possible with "scientific perspective." Theories or facts should be supported by logic and strong evidence. The philosopher of science looks for distinguishing characteristics of the research, the conditions that satisfy the correctness of the scientific explanation, the cognitive status of scientific laws and principles, and principles to be understandable (15). Many philosophers may consider Losee's ideas that are mentioned above outdated, deficient, or inadequate, especially in shedding light on the nature of social sciences. They can also oppose these analyses made here, understandably. However, these ideas are useful to give examples of neuroscience, mechanical "low back pain" (LBP). Here, it also should be remembered that philosophically there may be no such claim as "absolutely correct" or "absolute truth."

LBP is a "fact" that is commonly observed in most industrialized countries. The exact origin of the pain is unknown, and many structures were thought to play a role (20). LBP was presumed to have a mechanical origin that is commonly referred to clinically as spinal instability, but there was some associated uncertainty.

"Explanation of the fact:" In 1944, Knutsson started in vivo studies on clinical instability with the supposition that disk degeneration between the vertebrae causes abnormal movements. He did not use any words from the concept of "low back pain," and assumed that the clinical symptoms of disc degeneration were due to this instability. He used functional radiographs to relate clinical symptoms to retrodisplacement a vertebra during flexion. He introduced the "parallel displacement" and "abnormal tilting movements between the vertebrae" concepts (13). Much later, White and Panjabi explained in detail that the origin of the LBP was the clinical spinal instability. The concept of "clinical instability" was described as "the loss of the spine's ability to maintain its patterns of displacement under physiologic loads, so there is no initial or additional neurologic deficit, no major deformity, and no incapacitating pain" (30).

"Analysis of Procedures and Logic of Scientific Explanation:" Scientific views started to emerge after the explanation of the concept of clinical instability by scientists. Panjabi reinterpreted the definition of clinical instability as "a significant decrease in the capacity of the stabilizing system of the spine to maintain the intervertebral neutral zones within physiological limits," and he made new experimental observations by using new concepts such as "neutral position," "range of motion," "neutral zone," and "elastic zone" to achieve the logic of his scientific explanations (23).

Panjabi conceptualized the spinal stabilization system of the spine with its three subsystems: 1) the spinal column providing intrinsic stability, 2) the spinal muscles surrounding the spinal column and providing dynamic stability, and 3) the neural control unit evaluating and determining the requirements for stability and coordinating the muscle response (22).

Table I: The analysis of a scientific method (A Second-Order Discipline) with an Example (15)

\begin{tabular}{|c|c|c|}
\hline Level & Discipline & Subject-Matter \\
\hline 0 & & Facts: Low back pain (LBP) (20). \\
\hline 1 & Science & $\begin{array}{l}\text { Explanation of Facts: "The cause of LBP is spinal instability" (13). Clinical spinal instability } \\
\text { is "the loss of the spine's ability to maintain its patterns of displacement under physiologic } \\
\text { loads so there is no initial or additional neurologic deficit, no major deformity, and no } \\
\text { incapacitating pain" (23). The experiments showed that the stability of spine is provided by } \\
\text { three subsystems; spinal column (passive subsystem), spinal muscles (active subsystem) } \\
\text { and neural unit (passive subsystem) (22). Any injury or degeneration in these structures } \\
\text { causes a decrease in the capacity of the stabilizing system of the spine and hence LBP } \\
\text { (20). }\end{array}$ \\
\hline
\end{tabular}

Analysis of Procedures and Logic of Scientific Explanation: For explanation of

2 Philosophy of Science the scientific facts mentioned above, some concepts like passive subsystem, active subsystem, neural unit, neutral position, ROM, NZ, and EZ was introduced and used in experiments by the scientists (23).

Neutral position is the posture of the spine is provided with minimal muscular effort. Range of motion (ROM) is the entire range of the physiological intervertebral motion. Neutral zone (NZ) is that part of the ROM within which there is minimal resistance to intervertebral motion; it is the high flexibity and laxity zone. Elastic zone $(E Z)$ is that part of the ROM which is produced against a significant internal resistance; it is the high stiffness zone (23). 
After that, a large number of clinical, in vivo and in vitro research papers about mechanical LBP and instability emerged in the literature. Each of these papers tried to provide a logical explanation to LBP and instability by adding their own scientific views of what they observed from their works.

In a scientific article, presenting a logical analysis of applied procedures and having logical scientific explanations are both important. The philosophy of science evaluates science as a whole both physically and intellectually, and efforts to understand the relationship between the fact (phenomenon, event) and hypotheses/theories used for explanation of the fact.

\section{Practical Difficulties in the Application of Scientific Facts}

It is not always easy and possible to stick to the philosophy of science and act with a "scientific perspective" in neurosurgery practice because of human factors. For example: Objectivity, testability, and universality are among the fundamental features of "scientific attitude" or of the "scientific approach," which is very compatible with physics or chemistry science, especially due to the reliability factor and also the absence of any precondition regarding human involvement; however, in neurosurgical practice, particularly due to its impact on humans and the corresponding ethics involved, you cannot apply them precisely for every case. Neurosurgeons are frequently faced with uneasy intraoperative decisions and have to conduct a risk-benefit analysis, and choose the "middle path," a pathway of moderation and perfect balance, which was described by Lord Buddha (29). The "middle path" leads to a life that exists between the two extremes. Although the objective and universal scientific rules recommend maximal tumor resection for a significant survival in glial tumors, neurosurgeons can tail their resection and leave some tumor behind for functional benefit based on the tumor location and the patient's characteristics by considering the "middle path" philosophy (31). Preserving the postoperative quality of life or providing a life without neurological deficit may sometimes be more important than hard scientific rules such as objectivity and universality. Philosophical approach to the issues not only provides a systematic perspective but also intellectual and moral potentials for appropriate solutions (14).

\section{CONCLUSION}

The philosophy of science questions the concept of "scientific knowledge" and analyzes the procedures and observations for a logical explanation of these facts from a scientific perspective that is important for natural sciences in general and neurosurgery in particular.

Some problematic terms such as "observable" and "unobservable" objects and usage of concepts such as "dynamic" and "stabilization" in the philosophy of science in neurosurgery, which are based on entirely different categories, in the same scientific explanations are gradually increasing with the enormous technological advances in neuroscience.

Using these concepts in our neurosurgery practice will not only affect the basis of our "scientific knowledge" but also the relationships with our patients and colleagues. It is essential to "understand" and be "understandable" in daily practice and in the "scientific world." We should learn to bring "scientific perspectives" to these type of issues by using critical, analytical, and integrative features of philosophy.

\section{ACKNOWLEDGEMENTS}

The author thanks to Prof. Dr. Murat Bac from Middle East Technical University (METU), Department of Philosophy, Ankara, Turkey, for his valuable criticism of the article with constructive suggestions.

\section{REFERENCES}

1. Bac M: Philosophy of science. In: Tasdelen D (ed), Philosophy. Eskişehir: Anadolu University, 2010:93-115 (in Turkish)

2. Barseghyan H, Overgaard N, Rupik G: Scientific Progress. in Introduction to History and Philosophy of Science. Pressbooks. Available at: https://ecampusontario.pressbooks.pub/ introhps/chapter/chapter-5-scientific-progress/Accessed May 17, 2020

3. Basic assumptions of science. Understanding Science. University of California Museum of Paleontology. January 03, 2020 web site. Available at: https://undsci.berkeley.edu/ article/basic_assumptions. Accessed May 11, 2020

4. Criteriology. Online Wiktionary, the free dictionary, web site. Available at: https://en.wiktionary.org/wiki/criteriology Accessed May 04, 2020

5. Durant W: The Story of Philosophy. New York: Garden City Publishing, 1926:66

6. Durant W: The Story of Philosophy. New York: Garden City Publishing, 1926:138

7. Epistemology. Online Encyclopaedia Britannica web site. Available at: https://www.britannica.com/search?query=epistemology Accessed May 14, 2020

8. Ford RW: A reproducible spinal cord injury model in the cat. J Neurosurg 59(2):268-275, 1983

9. Grunberg T, Grunberg D: Philosophy of Science. Anadolu University: Eskişehir, 2012 (in Turkish).

10. Kashkoush A, Agarwal N, Paschel E, Goldschmidt E, Gerszten PC: Evaluation of a hybrid dynamic stabilization and fusion system in the lumbar spine: A 10 year experience. Cureus 8(6): e637, 2016

11. Khansur EM, Shah AH, Lacy K, Kuchakulla M, Komotar RJ: Novel immunotherapeutics for the treatment of glioblastoma: The last decade of research. Cureus 10(1):e2130, 2018

12. Klemke ED, Hollinger R, Kline AD: Introductory Readings in the Philosophy of Science. Buffalo, NY: Prometheus Books, 1980

13. Knutsson $F$ : The instability associated with disk degeneration in the lumbar spine. Acta Radiol 25:593-609, 1944

14. Likhterman LB: Clinical philosophy of modern neurosurgery. Russian J Neurosurg 20(1):94-102, 2018 (in Russ)

15. Losee J: A Historical Introduction to the Philosophy of Science, $4^{\text {th }}$ ed, Oxford: Oxford University Press, 2001 
16. Louis DN, Perry A, Reifenberger G, von Deimling A, FigarellaBranger D, Cavenee WK, Ohgaki H, Wiestler OD, Kleihues P, Ellison DW: The 2016 World Health Organization Classification of tumors of the central nervous system: A summary. Acta Neuropathol 131(6):803-820, 2016

17. Macintyre I: A hotbed of medical innovation: George Kellie (1770-1829), his colleagues at Leith and the Monro-Kellie doctrine. J Med Biogr 22(2):93-100, 2014

18. Marmarou A, Foda MA, van den Brink W, Campbell J, Kita $H$, Demetriadou K: A new model of diffuse brain injury in rats. Part I: Pathophysiology and biomechanics. J Neurosurg 80:291-300, 1994

19. McCormack HM, Horne DJ, Sheather S: Clinical applications of visual analogue scales: A critical review. Psychol Med 18: 1007-1019, 1988

20. Nachemson AL: Advances in low-back pain. Clin Orthop Relat Res 200:266-278, 1985

21. Ontology. Online Stanford Encyclopedia of Philosophy web site. Available at: https://plato.stanford.edu/entries/logicontology/ Accessed May 14, 2020

22. Panjabi MM: The stabilizing system of the spine. Part I. Function, dysfunction, adaptation, and enhancement. J Spinal Disord 5(4):383-389, 1992

23. Panjabi MM: The stabilizing system of the spine. Part II. Neutral zone and instability hypothesis. J Spinal Disord 5(4):390-397, 1992
24. Phenomenon. Online Encyclopaedia Britannica web site. Available at: https://www.britannica.com/topic/phenomenonphilosophy. Accessed May 14, 2020

25. Philosophy. Online Encyclopaedia Britannica web site. Available at: https://www.britannica.com/search?query=Philosophy. Accessed May 01, 2020

26. Philosophy. Online Etymology Dictionary web site. Available at: https://www.etymonline.com/search?q=philosophy. Accessed May 01, 2020

27. Philosophy. Online Lexico Dictionary web site. Available at: https://www.lexico.com/definition/philosophy. Accessed August 17,2020

28. Saladino A, Lamperti M, Mangraviti A, Legnani FG, Prada FU, Casali C, Caputi L, Borrelli P, DiMeco F: The semisitting position: Analysis of the risks and surgical outcomes in a contemporary series of 425 adult patients undergoing cranial surgery. J Neurosurg 127(4):867-876, 2017

29. Sharma BS: The philosophy of 'middle path' in neurosurgery. Neurol India 64:208-214, 2016

30. White AA, Panjabi MM: Clinical Biomechanics of the Spine, $2^{\text {nd }}$ ed, Philadelphia, PA: JB Lippincott, 1990

31. Yong RL, Lonser RR: Surgery for glioblastoma multiforme: Striking a balance. World Neurosurg 76(6):528-530, 2011 